\title{
The Impact of Near-Peer Teaching on Medical Students' Transition to Clerkships
}

Alexander C. Knobloch, MD, Christy J.W. Ledford, PhD; Sean Wilkes, MD, MSc;

Adam K. Saperstein, MD

BACKGROUND AND OBJECTIVES: The transition to clerkships is one of the most challenging times during medical school. To help students better cope, many schools have established transition-to-clerkship curricula. Such curricula may optimally prepare students through increasing their self-efficacy and response efficacy. We hypothesized that a small-group, near-peer-led format would be ideally suited to help students achieve these outcomes.

METHODS: During process improvement for a transition-to-clerkship curriculum, we conducted an informal focus group and subsequent survey of postclerkship students to guide curricular innovation, including incorporation of third- and fourth-year students as near-peer instructors in a seminar format. Seminars included three sequential small-group discussions focused on discrete topic areas and concluded with a large-group session highlighting salient discussion points. To evaluate the impact of this educational strategy, near-peer learners were surveyed before and after the seminars.

RESULTS: Junior student participants reported feeling more prepared to integrate into the health care team, develop a clerkship study plan, and access applicable, valuable study materials, both immediately following the seminars and 6 months later, demonstrating increased self-efficacy. These students placed equal or greater value on these topics as compared to students in previous year groups, demonstrating similar response efficacy.

CONCLUSIONS: This study demonstrated an increase in student self-efficacy that persisted 6 months postintervention, in addition to similar response efficacy. Future research could be directed toward: (1) investigating whether improvements in self-efficacy among students transitioning to clerkships are associated with improved clerkship performance and (2) studying outcomes for near-peer teachers.

(Fam Med. 2018;50(1):58-62.)

doi: 10.22454/FamMed.2018.745428

$\mathbf{T}$

he transition from preclinical to clinical training is recognized as one of the most challenging transitions faced during undergraduate medical education..$^{-3}$ To help students with this transition, medical schools have incorporated transition-to-clerkship courses into their curricula. ${ }^{1,4-6}$ Viewing these courses through the lens of Bandura's social cognitive theory, ${ }^{7,8}$ if students believe that they are prepared to perform behaviors taught during a transition-to-clerkship curriculum (self-efficacy) and believe that those behaviors will lead to better clerkship performance (response efficacy), they will be more likely to engage in those learned behaviors.

Near-peer teaching (NPT), in which seniors teach their juniors in the same educational track, ${ }^{9-15}$ may be optimally suited to enhance students' self-efficacy and response efficacy. Near-peer teaching promotes learning from an instructor who is more likely to express oneself in the learner's language (cognitive congruence). ${ }^{16-18}$ In addition, nearpeer teachers are often perceived as more approachable and are more likely to communicate with learners with an empathic attitude, which can offer a greater sense of safety in the learning environment (social congruence). ${ }^{16-18}$ Learning in an environment of cognitive and social congruence may be especially important during periods of increased stress, including transition to clerkships.

We implemented a near-peerled transition-to-clerkship seminar as part of our institution's transition-to-clerkship curriculum (TCC) and investigated the impact of this seminar on students' self-efficacy,

From Eglin Family Medicine Residency, Eglin AFB (Dr Knobloch); Department of Family Medicine, F. Edward Hébert School of Medicine, Uniformed Services University of the Health Sciences, Bethesda, MD (Drs Ledford and Saperstein); and the Department of Behavioral Health, Tripler Army Medical Center, Honolulu, HI (Dr Wilkes). 
hypothesizing enduring improvements related to three transition-to-clerkship topics. We also hypothesized that the perceived value (response efficacy) of the topics addressed in the near-peer seminar would remain consistent in a cohort comparison with the prior year group.

\section{Methods}

\section{Setting and Formative}

Evaluation

In December 2012, a 2-week, faculty-taught TCC was first taught at the F. Edward Hébert School of Medicine, Uniformed Services University of the Health Sciences for the class of 2015. In April 2013, as part of process improvement, students from this class participated in a focus group that evaluated the TCC, identifying topics of importance and areas for improvement. Using this feedback, we created and distributed an online, class-wide anonymous survey to gather additional feedback. This survey identified that (1) integrating into the health care team ( $72 \%$ of respondents) and (2) developing a study plan and accessing valuable study materials ( $91 \%$ of respondents) were topics perceived to be of greatest value for the TCC. Respondents felt neither of these topics was well addressed in the December 2012 TCC (28\% and $15 \%$, respectively). Near-peers were identified as the optimal instructors for this material (67\%), compared to online resources (20\%) and faculty (12\%), while $47 \%$ of respondents felt smallgroup discussion to be the optimal teaching modality for future TCCs as opposed to lecture (33\%) or online resources $(20 \%)$.

\section{Curriculum Development and Near-Peer Recruitment and Training}

Informed by survey responses, we designed a near-peer-led smallgroup seminar to be taught during the January 2014 TCC. Near-peer instructors were recruited via classwide communication to the entirety of the classes of 2014 and 2015 to maximize heterogeneity. Student volunteers were provided training, including an overview of seminar objectives and format and strategies for facilitation.

Near-Peer Small-Group Seminars The seminar format is detailed in Table 1. Groups of 7 to 10 near-peer learners were paired with 2 to 3 near-peer instructors during smallgroup discussion. To standardize course content, key questions asked in small groups were posted by instructors to a microblog platform ${ }^{19-20}$ and then addressed in a large-group Q\&A session. Additionally, students were given access to an online resource repository created by the near-peer instructors.
Data Collection and Analysis Surveys were sent via email to the class of 2016 prior to and immediately following their TCC, as well as 6 months later, and collected anonymously. We analyzed the difference between survey results using a oneway analysis of variance (ANOVA). Additionally, results from the survey sent to the class of 2015 (a control group not exposed to the near-peer seminar) were compared to the 6-month postseminar survey results using a one-way ANOVA. Data were analyzed using SPSS 22.0 (IBM, Armonk, NY). This study received an exempt determination from the university's institutional review board.

\section{Results}

Using a Likert-type scale, we compiled survey responses from the class of 2016, both prior to and following the near-peer-led small-group seminars (Table 2). Dramatic improvements were seen in students' perceived preparedness in each of the three topics covered by the seminars (Table 3). Students reported feeling more prepared to integrate into the inpatient and outpatient teams $(F[2,267]=43.9, P<0.001)$, develop a clerkship study plan $(F$ $[2,268]=57.5, P<0.001)$, and access clerkship study materials $(F$ $[2,268]=68.2, P<0.001)$, both immediately following the seminars and again 6 months later. Tukey post hoc comparison showed statistical

Table 1: Near-Peer-Led Transition to Clerkship Seminar Curriculum

\begin{tabular}{|l|l|}
\hline \multicolumn{1}{|c|}{ Station (Duration) } & \multicolumn{1}{c|}{ Topic } \\
\hline 1 (25min) & Seminar Overview and Near-Peer Instructor Introductions \\
\hline $2(35 \mathrm{~min})$ & $\begin{array}{l}\text { Integrating into the Health Care Team (ie, rounding styles, etiquette, priorities; team member } \\
\text { roles and responsibilities; overview of a typical inpatient/outpatient day) }\end{array}$ \\
\hline $3(35 \mathrm{~min})$ & Clerkship Study Plan and Clerkship Study Materials \\
\hline $4(35 \mathrm{~min})$ & $\begin{array}{l}\text { Miscellaneous Topics } \text { (ie, travel questions, well-being, clerkship site info, residency/specialty } \\
\text { questions })\end{array}$ \\
\hline $5(25 \mathrm{~min})$ & $\begin{array}{l}\text { Final Q\&A, Microblog Question Review, Breakout for Individual Questions to Near-Peer } \\
\text { Instructors }\end{array}$ \\
\hline
\end{tabular}

${ }^{\text {a }}$ During the first seminar, small groups were able to address both clerkship study plan and materials within a single, 35-minute session. Consequently, the third 35-minute small-group session was used to address miscellaneous topics, guided by junior medical students' questions, most of which focused on "self-care." 
Table 2: Class of 2016 Respondent Demographics ${ }^{a}$

\begin{tabular}{|c|c|c|c|c|}
\hline & & $\begin{array}{l}\text { Class of } 2016 \\
\text { Preseminar } \\
\text { Respondents }\end{array}$ & $\begin{array}{l}\text { Class of } 2016 \\
\text { Immediate } \\
\text { Postseminar } \\
\text { Respondents }\end{array}$ & $\begin{array}{c}\text { Class of } 2016 \\
\text { 6-month Postseminar } \\
\text { Respondents }\end{array}$ \\
\hline \multicolumn{2}{|l|}{ Sample size $(n)$} & 121 & 75 & 75 \\
\hline \multicolumn{2}{|c|}{ Survey response rate ${ }^{b}$} & $71 \%$ & $44 \%$ & $44 \%$ \\
\hline \multirow{2}{*}{ Gender } & Female & $44(36 \%)$ & $27(36 \%)$ & $24(32 \%)$ \\
\hline & Male & $75(62 \%)$ & $47(63 \%)$ & $50(67 \%)$ \\
\hline \multirow{4}{*}{ Age } & $<25$ years old & $44(36 \%)$ & $26(35 \%)$ & $16(21 \%)$ \\
\hline & 25-29 years old & $47(39 \%)$ & $31(41 \%)$ & $41(55 \%)$ \\
\hline & 30-34 years old & $18(15 \%)$ & $12(16 \%)$ & $12(16 \%)$ \\
\hline & $>34$ years old & $10(8 \%)$ & $5(7 \%)$ & $5(7 \%)$ \\
\hline \multicolumn{2}{|c|}{ Within mentor relationship } & $50(41 \%)$ & $32(43 \%)$ & $41(55 \%)$ \\
\hline \multicolumn{2}{|c|}{ Clinical experience before medical school } & $65(54 \%)$ & $36(48 \%)$ & $40(53 \%)$ \\
\hline \multicolumn{2}{|c|}{ Family member in medical field } & $39(32 \%)$ & $17(23 \%)$ & $27(36 \%)$ \\
\hline \multirow{4}{*}{$\begin{array}{l}\text { Time spent } \\
\text { interacting with } \\
\text { medical field as } \\
\text { patient or family } \\
\text { member }\end{array}$} & Very little & $37(31 \%)$ & $18(24 \%)$ & $26(35 \%)$ \\
\hline & $\begin{array}{l}\text { Some_-about what } \\
\text { I would expect to be } \\
\text { average for someone my } \\
\text { age }\end{array}$ & $62(51 \%)$ & $42(56 \%)$ & $40(53 \%)$ \\
\hline & $\begin{array}{l}\text { A lot of time in the patient } \\
\text { role }\end{array}$ & $6(5 \%)$ & $2(3 \%)$ & $2(3 \%)$ \\
\hline & $\begin{array}{l}\text { A lot of time in a family } \\
\text { member/caretaker role }\end{array}$ & $13(11 \%)$ & $10(13 \%)$ & $6(8 \%)$ \\
\hline \multicolumn{2}{|c|}{$\begin{array}{l}\text { Additional medical experiences outside } \\
\text { curriculum }\end{array}$} & $78(64 \%)$ & $45(60 \%)$ & $49(65 \%)$ \\
\hline \multirow{5}{*}{$\begin{array}{l}\text { Preclerkship study } \\
\text { habits }\end{array}$} & $\begin{array}{l}\text { Alone nearly all of the } \\
\text { time }\end{array}$ & $26(21 \%)$ & $19(25 \%)$ & $24(32 \%)$ \\
\hline & Alone most of the time & $54(45 \%)$ & $32(43 \%)$ & $32(43 \%)$ \\
\hline & Half and half & $23(19 \%)$ & $15(20 \%)$ & $12(16 \%)$ \\
\hline & $\begin{array}{l}\text { With others most of the } \\
\text { time }\end{array}$ & $12(10 \%)$ & $6(8 \%)$ & $4(5 \%)$ \\
\hline & $\begin{array}{l}\text { With others nearly all of } \\
\text { the time }\end{array}$ & $2(2 \%)$ & $0(0 \%)$ & $1(1 \%)$ \\
\hline
\end{tabular}

${ }^{\text {a }}$ Demographic data not collected in the survey sent to the class of 2015.

${ }^{\mathrm{b}}$ Total class size was 170 students.

difference at both postseminar time points for all three topics.

When comparing the class of 2015 to the class of 2016 , both classes agreed that there was value in learning how to develop a study plan, while the class of 2016 ascribed significantly greater value to learning how to integrate into the health care team $(F[1,198]=8.887, P<0.01)$.

\section{Discussion}

Implementation of a near-peer-led small-group seminar within our university's TCC was successful in improving perceptions of preparedness (self-efficacy) in each topic area. This improvement persisted 6 months postintervention. In light of the findings of a recent systematic review that identified adapting one's learning style to the clinical environment (developing a study plan) and professional socialization (learning one's role in the health care team) as common challenges for students making the clerkship transition, the improvement in students' perceived preparedness after attending our seminar is encouraging. ${ }^{21}$ Additionally, students placed equal or greater value on these topics as compared to students in previous year groups, demonstrating similar response efficacy.

Three factors limited our study's findings. The first is that as surveys were anonymous, we were unable to link responses from individual participants when comparing perceived preparedness across time points. Thus, we were limited 
Table 3: Effects of Near-Peer-Led Small-Group Transition-to-Clerkship

Seminars on Class of 2016 Self- and Response Efficacy

\begin{tabular}{|c|c|c|c|c|c|}
\hline & \multicolumn{4}{|c|}{ Mean Survey Responses ${ }^{a}$} & \multirow[b]{2}{*}{$F(P)$} \\
\hline & $\begin{array}{l}\text { Class of } 2015 \\
\quad(n=79)\end{array}$ & $\begin{array}{l}\text { Class of } 2016 \\
\text { Preintervention } \\
\qquad(n=121)\end{array}$ & $\begin{array}{l}\text { Class of } 2016 \\
\text { Immediate } \\
\text { Postintervention } \\
\quad(n=75)\end{array}$ & $\begin{array}{l}\text { Class of } 2016 \\
\text { 6-month } \\
\text { Postintervention } \\
\quad(n=74)\end{array}$ & \\
\hline \multicolumn{6}{|c|}{ Preparedness (Measure of Self-Efficacy) } \\
\hline $\begin{array}{l}\text { To integrate into the inpatient } \\
\text { and outpatient healthcare team }\end{array}$ & - & 2.59 & 3.71 & 3.34 & $43.9(<0.001)^{\mathrm{b}}$ \\
\hline To develop a clerkship study plan & - & 2.64 & 3.87 & 3.42 & $57.5(<0.001)^{b}$ \\
\hline $\begin{array}{l}\text { To access applicable, highly } \\
\text { valuable study materials to } \\
\text { be used during core clerkship } \\
\text { rotations }\end{array}$ & - & 2.76 & 4.09 & 3.71 & $68.2(<0.001)^{\mathrm{b}}$ \\
\hline \multicolumn{6}{|c|}{ Value (Measure of Response Efficacy) } \\
\hline To develop a clerkship study plan & 4.42 & 4.34 & - & - & $\mathrm{ns}^{\mathrm{c}}$ \\
\hline $\begin{array}{l}\text { To integrate into the inpatient } \\
\text { and outpatient health care team }\end{array}$ & 3.84 & 4.21 & - & - & $\begin{array}{c}8.9 \\
(<0.01)\end{array}$ \\
\hline
\end{tabular}

a Each item measured on 1 (negative) to 5 (positive) scale.

${ }^{\mathrm{b}}$ Tukey post hoc comparison showed statistical difference at both postseminar time points.

${ }^{\mathrm{c}} \mathrm{ns}=$ not significant

to using a one-way ANOVA to best analyze our results, despite having to violate the assumption of independence between samples in this test. However, as our analysis did reveal similar demographic compositions at each time point, our findings were more likely to represent improvements in perceived preparedness rather than changes due to demographic shifts in survey respondents at each time point. Secondly, as perceived preparedness was not measured among members of the class of 2015, we were unable to compare perceived preparedness between the intervention group and a control group without exposure to a near-peer-taught TCC. Thus, while it is encouraging that an improvement in self-efficacy persisted among members of the intervention group at 6 months, it is possible that there are other factors, like students' experiences during clerkships, that impacted perceptions of preparedness for which we did not account. Finally, respondents' gender closely matched that of our student population (64.9\% male, $35.1 \%$ female) but not that of medical schools across the country (53.6\% male, $46.4 \%$ female) which may limit generalizability. ${ }^{22}$

This study is the first to evaluate the impact of near-peer teaching on learners' self-efficacy during the transition-to-clerkship period. Future research could be directed toward adapting our seminar into curricula at other institutions, determining whether these improvements in self-efficacy extend to student performance during clerkships (as it has in other academic environments), ${ }^{23,24}$ and the effects of such seminars on near-peer teachers.

ACKNOWLEDGMENTS: The authors would like to thank the USU Classes of 2014-2016 who participated in this study.

Conflicts of Interest/Financial Support: The authors report no conflicts of interest. Financial support was not received for this project. The opinions and assertions contained herein are the private views of the authors and should be construed neither as official nor as reflecting the views of the US Department of Defense, the US Air Force, US Army, US Navy, or the Uniformed Services University.

Presentations: This study was presented at the 2015 Society of Teachers of Family Medicine Conference on Medical Student Education, San Antonio, TX
CORRESPONDING AUTHOR: Address correspondence to Dr Knobloch, Eglin Family Medicine Residency, 96th Medical Group, 307 Boatner Road, Eglin AFB, FL 32542. 850-883-9501. Fax: 850-883-8192. alexander.knobloch.2@us.af.mil.

\section{References}

1. O’Brien BC, Poncelet AN. Transition to clerkship courses: preparing students to enter the workplace. Acad Med. 2010;85(12):1862-1869.

2. Prince KJ, Boshuizen HP, van der Vleuten CP, Scherpbier AJ. Students' opinions about their preparation for clinical practice. Med Educ. 2005;39(7):704-712.

3. Atherley AE, Hambleton IR, Unwin N, George C, Lashley PM, Taylor CG Jr. Exploring the transition of undergraduate medical students into a clinical clerkship using organizational socialization theory. Perspect Med Educ. 2016;5(2):78-87.

4. Taylor JS, George PF, MacNamara MM, et al. A new clinical skills clerkship for medical students. Fam Med. 2014;46(6):433-439.

5. Sakai DH, Fong SF, Shimamoto RT, Omori JS, Tam LM. Medical school hotline: transition to clerkship week at the John A. Burns School of Medicine. Hawaii J Med Public Health. 2012;71(3):81-83.

6. Chittenden EH, Henry D, Saxena V, Loeser H, O'Sullivan PS. Transitional clerkship: an experiential course based on workplace learning theory. Acad Med. 2009;84(7):872-876.

7. Bandura A. Self-efficacy: toward a unifying theory of behavioral change. Psychol Rev. 1977;84(2):191-215 
8. Williams DM, Anderson ES, Winett RA. A review of the outcome expectancy construct in physical activity research. Ann Behav Med. 2005;29(1):70-79.

9. Whitman NA. Peer Teaching: To Teach is To Learn Twice. Washington, DC: Association for the Study of Higher Education; 1988. ASHEERIC Higher Education Report; vol 4.

10. Nelson CA, Frosch Z, Lapin J, Kogan JR. Facilitating the clerkship transition through near-peer-led 'student reports'. Med Educ. 2014;48(5):532-533.

11. Naeger DM, Conrad M, Nguyen J, Kohi MP, Webb EM. Students teaching students: evaluation of a "near-peer" teaching experience. Acad Radiol. 2013;20(9):1177-1182.

12. Meller SM, Chen M, Chen R, Haeseler FD. Near-peer teaching in a required third-year clerkship. Yale J Biol Med. 2013;86(4):583-589.

13. Blank WA, Blankenfeld H, Vogelmann R, Linde K, Schneider A. Can near-peer medical students effectively teach a new curriculum in physical examination? BMC Med Educ. 2013;13(1):165-170.

14. Yu TC, Wilson NC, Singh PP, Lemanu DP, Hawken SJ, Hill AG. Medical students-asteachers: a systematic review of peer-assisted teaching during medical school. Adv Med Educ Pract. 2011;2:157-172.
15. Alford CL, Currie DM. Introducing first-year medical students to clinical practice by having them "shadow" third-year clerks. Teach Learn Med. 2004;16(3):260-263.

16. Benè KL, Bergus G. When learners become teachers: a review of peer teaching in medical student education. Fam Med. 2014;46(10):783787.

17. Lockspeiser TM, O'Sullivan P, Teherani A, Muller J. Understanding the experience of being taught by peers: the value of social and cognitive congruence. Adv Health Sci Educ Theory Pract. 2008;13(3):361-372.

18. Ten Cate O, Durning S. Peer teaching in medical education: twelve reasons to move from theory to practice. Med Teach. 2007;29(6):591599.

19. Saperstein AK, Ledford CJW, Servey J, Cafferty LA, McClintick SH, Bernstein E. Microblog use and student engagement in the large-classroom setting. Fam Med. 2015;47(3):204-209.

20. Forgie SE, Duff JP, Ross S. Twelve tips for using Twitter as a learning tool in medical education. Med Teach. 2013;35(1):8-14.

21. Surmon L, Bialocerkowski A, Hu W. Perceptions of preparedness for the first medical clerkship: a systematic review and synthesis. BMC Med Educ. 2016;16(1):89-99.
22. Association of American Medical Colleges. Total Graduates by U.S. Medical School and Sex, 2011-2012 through 2015-2016. https://www. aamc.org/download/321532/data/factstableb2-2. pdf. Accessed March 9, 2017.

23. Chemers MM, Hu L, Garcia BF. Academic self-efficacy and first-year college student performance and adjustment. J Educ Psychol. 2001;93(1):55-64.

24. Zimmerman BJ, Bandura A, Martinez-Pons M Self-motivation for academic attainment: the role of self-efficacy beliefs and personal goa setting. Am Educ Res J. 1992;29(3):663-676. 